\title{
Urdimento
}

Revista de Estudos em Artes Cênicas

E-ISSN: 2358.6958

\section{Teatro como ferramenta para entender o mundo}

Entrevista com Helgard Haug concedida à Giorgio Zimann Gislon

\section{Para citar este artigo:}

GISLON, Giorgio Zimann. Teatro como ferramenta para entender 0 mundo. Entrevista com Helgard Haug. Urdimento, Florianópolis, v. 1, n. 40, mar./abr. 2020.

do) DOI: http:/dx.doi.org/10.5965/2358695801402021e0500 
Teatro como ferramenta para entender o mundo

Entrevista com Helgard Haug concedida à Giorgio Zimann Gislon¹

\begin{abstract}
Resumo
Nesta entrevista, realizada no teatro Künstlerhaus Mousonturm de Frankfurt em fevereiro de 2019, a diretora Helgard Haug do grupo Rimini Protokoll afirma seu posicionamento crítico e teórico sobre teatro. Dentre observações sobre as suas motivações artísticas e sobre modos de criação teatral, ela comenta especialmente os trabalhos: DO's \& DON'TS - Eine Fahrt nach allen Regeln der Stadt (2018), Situation Rooms (2013), Welt-Klimakonferenz (2014) e Weltzustand Davos (Staat 4) (2018).
\end{abstract}

Palavras-chave: Atores não profissionais. Mecanismos de interação. Participação. Teatro documentário. Teatro do real.

Theater as a tool to understand the world

\begin{abstract}
In this interview, carried out at the Künstlerhaus Mousonturm theatre in Frankfurt in February 2019, Helgard Haug, director of Rimini Protokoll, states her critical and theoretical positioning towards theatre. Among observations of her artistic reasons and creation processes, she particularly comments on DO's \& DON'Ts - Eine Fahrt nach allen Regeln der Stadt (2018), Situation Rooms (2013), Welt-Klimakonferenz (2014) e Weltzustand Davos (Staat 4) (2018).
\end{abstract}

Keywords: Documentary theatre. Interaction mechanisms. Non-professional actors. Participation. Theatre of the real.

\title{
Teatro como herramienta para comprender el mundo
}

\section{Resumen}

En esta entrevista, realizada en el teatro Künstlerhaus Mousonturm en Frankfurt en febrero de 2019, la directora Helgard Haug del grupo Rimini Protokoll afirma su posicionamiento critico y teórico sobre el teatro. Entre las observaciones sobre sus razones artísticas y sobre los modos de creación, ella comenta especialmente: DO's \& DON'Ts - Eine Fahrt nach allen Regeln der Stadt (2018), Situation Rooms (2013), Welt-Klimakonferenz (2014) e Weltzustand Davos (Staat 4)(2018).

Palabras clave: Actores no profesionales. Mecanismos de interacción. Participación. Teatro documentario. Teatro de lo real. 


\section{Urdimento}

Figura 1 - Helgard Haug²

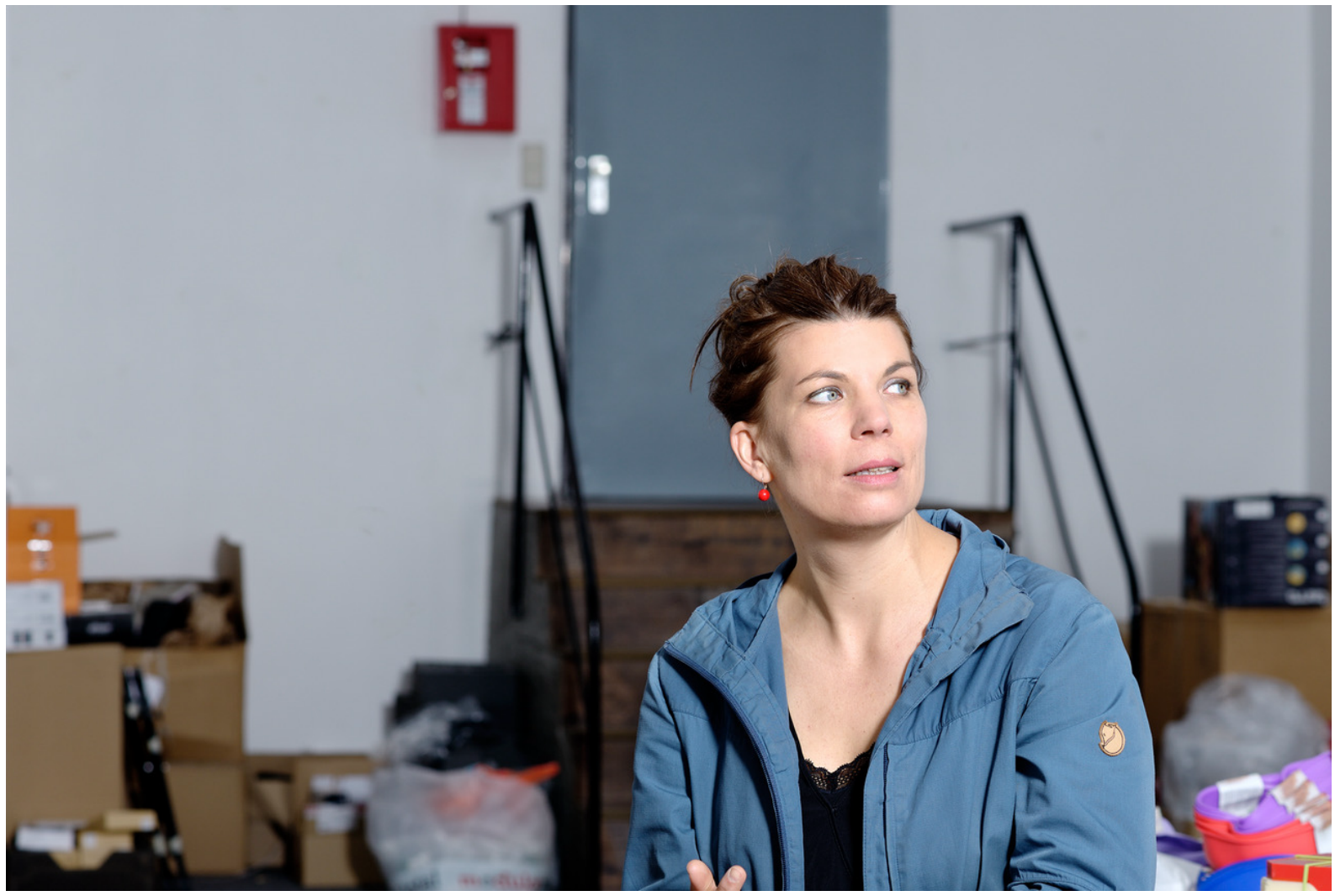

Helgard Haug é diretora e dramaturga e compõe, junto com Daniel Wetzel e Stefan Kaegi, o Rimini Protokoll. O grupo foi criado no começo dos anos 2000, em Giessen na Alemanha, e é de uma geração pouco posterior à descrita por HansThies Lehmann em Teatro Pós-Dramático (2007). O grupo se caracteriza pelo trabalho com múltiplas linguagens e gêneros artísticos, tais como: teatro do real, teatro documentário, teatro com atores não profissionais, performance, instalação, peça radiofônica, entre outros.

Junto com outros grupos importantes na renovação pós-dramática da cena

\footnotetext{
${ }^{2}$ Helgard Haug nasceu em 1969 e se formou em artes cênicas, junto com os outros integrantes do Rimini Protokoll, no Institut für Angewandte Theaterwissenschaft da Justus-Liebig-Universität na cidade de Gießen. Esse Instituto é conhecido na Alemanha como um centro inovador de formação de artistas em artes cênicas no campo expandido e híbrido com outros linguagens artísticas como cinema, performance art, rádio e vídeo. O currículo completo e mais informações sobre a diretora e o trabalho do Rimini Protokoll podem ser encontrados em: https://www.rimini-protokoll.de/website/en/about-hh Acesso em: 25 de nov. de 2020.
} 
alemãa ${ }^{3}$ o Rimini Protokoll foi muitas vezes produzido no começo de sua trajetória pelo Teatro HAU (Hebbel am Ufer) de Berlim e hoje apresenta suas peças nos cinco continentes. Inclusive, nos últimos anos, apresentou ou produziu projetos em cidades latino-americanas como Buenos Aires, Caruaru, Havana, Lima, Porto Alegre, Rio de Janeiro, Salvador, Santiago do Chile e São Paulo.

Nessa entrevista, realizada no Teatro Künstlerhaus Mousonturm ${ }^{4}$ de Frankfurt em fevereiro de 2019, Haug afirma seu posicionamento crítico e teórico sobre teatro e comenta, especialmente, os trabalhos: DO's \& DON'Ts - Eine Fahrt nach allen Regeln der Stadt ${ }^{5}$ (2018), Situation Rooms ${ }^{6}$ (2013), Welt-Klimakonferenz ${ }^{7}$ (2014) e Weltzustand Davos (Staat 4) ${ }^{8}$ (2018).

\footnotetext{
${ }^{3}$ A cena alemã contemporânea se caracteriza pela existência de vários teatros estatais com atores, diretores, dramaturgos e técnicos com contratos de trabalho fixos de longo prazo e subsidiados por vultosas verbas públicas. Ao mesmo tempo que isso garante uma grande quantidade de realizações teatrais com estrutura adequada de trabalho, também gera uma tendência à fixidez de linguagem e a encenação de textos clássicos com formas, na maior parte das vezes, dramáticas. O Teatro HAU de Berlim durante e após ser dirigido pelo produtor Matthias Lilienthal se notabilizou pela fomento a produção em formatos pós-dramáticos. Assim, ali encontraram um local de apoio à criação e um espaço de apresentação, além do Rimini Protokoll, grupos alemães como She She Pop, Gob Squad, entre outros. Além disso, o HAU se tornou importante espaço de apresentação na Alemanha para artistas estrangeiros como: El Conde de Torrefiel, Jérôme Bel, Lia Rodrigues, Marcelo Evelin, Philippe Quesne, Rabih Mroué, Toshiki Okada, entre outros. Mais informações sobre o Teatro HAU podem ser consultadas em: https://www.hebbel-am-ufer.de/en/ Acesso em: 25 de nov. de 2020.
}

${ }^{4}$ O Teatro Künstlerhaus Mousonturm em Frankfurt tem um papel parecido com o do HAU em Berlim, porém, com uma estrutura e capacidade de fomento à produção muito menor. O site desse Teatro pode está disponível em: https://www.mousonturm.de/ Acesso em: 25 de nov. de 2020.

${ }^{5}$ DO's \& DON'Ts - Eine Fahrt nach allen Regeln der Stadt se trata de um passeio, de uma plateia de cerca de cinquenta pessoas, a bordo de um caminhão adaptado pelas ruas de uma cidade. Nesse passeio, é explorada a teatralidade do cotidiano e o desconhecimento dos habitantes de suas próprias cidades, além de ser narrada a história de uma jovem adolescente com os dilemas próprios da sua idade. Conferir: https://www.riminiprotokoll.de/website/en/project/do-s-don-ts Acesso em: 25 de nov. de 2020.

6 Situation Rooms é um mecanismo de interação direta do público que coloca os espectadores em vários papéis diferentes de profissionais envolvidos no mercado mundial de armas. Conferir: https://www.riminiprotokoll.de/website/en/project/situation-rooms Acesso em: 25 de nov. de 2020.

7 Welt-Klimakonferenz simula a conferência da ONU que tenta dar respostas objetivas ao problema do aquecimento global. Conferir: https://www.rimini-protokoll.de/website/en/project/welt-klimakonferenz Acesso em: 25 de nov. de 2020.

8 Weltzustand Davos (Staat 4)é uma criação com atores não profissionais e com um mecanismo de interação direta do público que conta a história e mostra o funcionamento dos encontros do Fórum Econômico Mundial. Conferir: ttps://www.rimini-protokoll.de/website/en/project/weltzustand-davos-staat-4 Acesso em: 25 de nov. de 2020. 


\section{Depois de vinte anos, o que mantém você interessada em fazer teatro?}

Para mim é uma ferramenta para tentar entender o mundo um pouco melhor. Foi assim que começou, eu tinha uma paixão pelo teatro e queria fazer teatro. Mas, por outro lado, eu queria de algum modo, como uma jornalista, entender como certos campos são organizados, como as pessoas vivem as suas vidas, como as estruturas da sociedade são construídas, como vivemos da maneira que vivemos e como outras pessoas vivem da maneira que vivem. Sempre usei teatro, os instrumentos do teatro, para estar mais perto das respostas e também para ser mais precisa nas minhas questões. Eu percebi que o teatro possibilita isso e que as perguntas abrem histórias. Eu posso contatar alguém, eu posso perguntar se podemos conversar, se podemos fazer uma entrevista. Eu posso convidar pessoas para o palco para revelar coisas que outras pessoas não sabem. Há diferentes formas que eu gosto de explorar, fazer isso no palco, nos locais específicos, nas instituições, nas fábricas, eu procuro convidar o público a ir para esses lugares e faço isso com técnicas de contação de histórias, usando diferentes técnicas, convidando pessoas de diferentes campos.

Enquanto eu tiver perguntas eu provavelmente não pararei de trabalhar. É sempre uma questão de quanto teatralizado, quanto isso é teatro, quanto é feito no palco. E também é sempre uma questão de balanceamento. Depois de uma grande produção de uma peça de palco, eu sempre penso: "agora é tempo de fazer uma pintura, de fazer uma peça radiofônica, ou fazer algo diferente". Para não cair no perigo da repetição e entrar na rotina em que se pode facilmente estagnar. Essa é a razão para as várias diferentes formas que nós estamos usando, que eu estou usando. É sempre uma fome, depois de uma produção, uma fome de uma nova forma de trabalhar, de outra forma de organização. O termo teatro, nós o colocamos de maneira tão larga que talvez todos os nossos fazeres artísticos podem ser enquadrados como teatro. Então, enquanto houver questões, eu farei teatro. 


\section{Para você o teatro é principalmente uma forma de pesquisar a realidade?}

Sim, mas não é somente a realidade dos fatos puros, é sobre a realidade das pessoas. É para entender os motivos pelos quais as pessoas fazem o que estão fazendo. Por exemplo, se você olhar para Situation Rooms, nosso maior foco, nosso foco no conteúdo, estava em armas, acordos, negociatas. Em pessoas de quem a realidade ou biografia estava marcada pelas armas, ou determinada por armas, armamentos. Era verdadeiramente algo que eu tentava entender na sua totalidade. Não era julgar, não era formular uma opinião, ou um comentário, algo que você pode colocar por cima da complexidade, como uma manchete. Era entrar na lógica da pessoa, isso era o mais fascinante para mim, porque elas são pessoas do jeito que são, em todo os seus detalhes estranhos. E era para tentar entender uma pessoa que politicamente está totalmente no outro lado, fazendo coisas que politicamente eu definitivamente julgaria como diabólicas, como não boas. Por outro lado, tem um ser humano atrás dessas decisões. E o teatro seguramente é sobre olhar para os conflitos humanos e as característica humanas, é isso que eu tento entender. No começo, eu pensava que o teatro era sobre eu aprender e sobre eu abrir portas, mas agora eu penso que entender é o que teatro pode fazer.

\section{Numa peça como Do's and Dont's - Eine Fahrt nach allen Regeln der Stadt, por exemplo, você tem interesse de, além de entender, também deixar o público um pouco desconfortável com a realidade?}

Isso acontece. É uma coisa boa que aconteça. Geralmente, com a ferramenta deste caminhão o que a gente faz é enquadrar a realidade de alguma forma. O que você vê é na maior parte do tempo as pessoas, o que as pessoas veem na peça é o que elas vivem na cidade. Claro que pode haver pessoas que não vivem naquela cidade em que a peça está acontecendo. Mas, normalmente, você olha sua própria cidade e sua própria realidade. Você vai para cruzamentos em que você normalmente passa, quando está no seu caminho diário. E sentar no caminhão e 
olhar pela janela transforma a rua num palco, as pessoas rapidamente começam a parecer teatrais. Para mim é sempre muito emotivo, eu vejo de repente minha própria realidade com um sentimento melancólico. Porque você vê detalhes e momentos que fazem você se sentir melancólico ou até triste. Mas no fundo é um simples cruzamento, pelo qual você no dia a dia cruza a rua, sem essa emoção. Isso é o que caminhão faz, isso é o que o vidro faz: sentir-se seguro por trás desse vidro e olhar para a cidade. Por isso todo o tópico sobre monitoramento e controle.

E claro também o tópico sobre a adolescência, sobre o que é essa nova geração repetindo o que eles foram ensinados, depois rompendo e talvez mais tarde se rearranjando com tudo isso. A maneira pelas quais os motoristas estão fazendo isso, é tudo parte de diferentes passos nas próprias vidas deles. Você sabe a maneira pela qual você ficou assustado ou perplexo quando era uma criança e queria tornar tudo simples, claro e fácil. A adolescência é a idade em que tudo fica mais complexo, em que você tenta criar suas próprias regras, em que você está bravo ou com raiva das regras que são dadas. E o último passo, que é representado pelo motorista, em que você tenta se arranjar com o sistema e encontrar suas próprias brechas e possibilidades e você não é mais tão confrontativo com a sociedade. E é o que eu experienciei, é sobre o que eu gostaria de tornar as pessoas conscientes, você flutua entre esses diferentes níveis. É isso o que eu acredito que se vê através do protagonista, pelos olhos deles, quando você acompanha os passos dele.

Os projetos do Rimini Protokoll são muitas vezes vistos como projetos de participação no teatro, mas, em projetos como Situation Rooms e DO's \& DON'Ts - Eine Fahrt nach allen Regeln der Stadt, a questão seja talvez mais mostrar as restrições da participação. Você concorda com essa afirmação? Por que escolher fazer dessa maneira e não deixar as pessoas terem escolhas que alterariam o andar da peça?

Há outros exemplos, onde se dá responsabilidade para o público. Nos dois exemplos que a gente está discutindo, as pessoas realmente não tem agência. Em Situation Rooms, as pessoas estão vivendo a vida dos protagonistas, mas é tudo 
controlado e nós não queremos que as pessoas sejam criativas lá, porque não funcionaria. Se você decidir, "oh eu gostaria de ficar aqui, não gostaria de seguir o roteiro", você estragaria a apresentação para você mesmo e você estragaria a apresentação para os outros também. E é provavelmente por isso que funciona, porque as pessoas percebem que estragariam para os outros também. Em Situation Rooms, nós realmente queríamos criar um mecanismo cronometrado, um sistema. Nós somos todos, de uma maneira ou outra, parte disso. Não há escolha. É claro que você pode tentar sair totalmente do sistema, de alguma forma. Primeiro, nós não queríamos apenas criar uma situação, onde as pessoas sentassem, olhassem e julgassem. Você escuta a história de alguém e como uma audiência você sempre julga. É algo provavelmente muito natural, você tenta encontrar: isso é verdade? Isso é certo? Eu concordo? Eu gosto dessa pessoa? Eu sinto que isso é feio para mim?

Para prevenir isso, nós queríamos ter esse outra camada, essas pessoas que não estão presentes. E você precisa conhecer eles, estar na pele deles, você aprende mais, mas, então, você já é parte do sistema. Isso é algo que escolhemos, que achamos importante de mostrar, que não há maneira de sentar e estar fora disso. Nós estamos dentro disso. E para fazer isso funcionar você segue instruções, você tem um papel e você segue instruções. Isso é como os militares funcionam e isso é como a sociedade funciona, nós temos um papel e nós seguimos instruções. Durante Situation Rooms, num momento você percebe, eu não sou apenas parte da minha história, mas eu sou parte da história dos outros também. Se eu não tomar conta do tempo e não cuidar das instruções, isso estragaria a experiência dos outros participantes. De outro lado, há uma responsabilidade de sentir isso. E as pessoas são muito responsáveis. Apesar de que na realidade há vários exemplos de pessoas que não se importam com o que acontece com os outros. Isso cria outra camada, na peça se mostra que as pessoas ligam para o que acontece com as outras e isso cria uma pequena comunidade frágil entre os membro da audiência.

Temos outro exemplo, a Welt-Klimakonferenz, onde você é um delegado, você representa um país. Você não é totalmente livre, você tem instrução, você 
tem informação e você conhece o dilema em que seu país está colocado. Se você quer mudar sua economia para uma base de recursos renováveis, mas você está atado numa estrutura montada com combustíveis fósseis, você sabe que pode fazer algumas escolhas até certo limite. Nessa peça, entretanto, o participante pode fazer escolhas reais. Por exemplo, no modo com que você se comunica, no modo que você no final faz a escolha e a votação. A ideia geral da peça, porém, é outra vez fazer as pessoas experienciar o que é essa complexidade, como é entrar dentro dessa complexidade, onde há muitas informações, mas há muitas restrições também. O que é diferente do discurso fácil de "nós temos apenas que fazer isso e aquilo e o mundo será um mundo melhor'. Isso é uma boa maneira de tocar sentimentos, mas não é o que acontece na realidade, não é o que está acontecendo nessas conferências, não é a maneira como são tomadas as decisões. No teatro, eu penso que é interessante experienciar a complexidade, primeiro de tudo, isso é o que eu posso fazer, há limites, conhecer os seus limites e dentro desses limites perceber o que você pode fazer. Não há apenas um mundo bonito, agradável, de fantasia cor de rosa.

\section{O que você diria a uma crítica que apontasse essa posição de conhecer os limites como politicamente estática? Na realidade podemos ir além disso? Você está interessada em responder essa pergunta?}

Sim, com certeza. É ótimo que as pessoas procurem essa resposta no mundo real. Mas na Welt-Klimakonferenz, o que pensamos foi: "vamos pensar nessa conferência como um drama. E vamos olhar para ela como um tipo de drama". Não era uma questão de oferecer soluções, mas uma questão de observar o que estava acontecendo lá. Na realidade, é claro que espero que haja soluções, é a única maneira de caminhar. Mas, no teatro, o que normalmente acontece no teatro é o "e se..." e nós temos um grande sonho e nós podemos inventar tudo e passar uma hora com um ingresso barato vivendo num fantástico mundo inventado. Para isso as pessoas vão ao teatro, para isso as pessoas vão ao cinema. E esse mundo não está acontecendo na realidade. Minha parte desse mundo 
teatral é: vamos conectá-lo com a realidade e vamos usar isso. É claro que a imaginação e a fantasia têm um papel. Mas e se olharmos para a realidade? E se utilizarmos isso para entender melhor a realidade?

\section{Recentemente, pude assistir a peça Weltzustand Davos (Staat 4) que conecta o que talvez sejam os dois principais procedimentos de criação de peças do Rimini Protokoll: projetos com não atores e dispositivos de participação. Como você conta a história do grupo em relação a esses dois procedimentos de criação?}

Eu escuto as pessoas contando isso, que fizemos esse trajeto. Talvez seja uma impressão de quem olha à distância. Eu nunca senti que estivéssemos mudando. Para mim, todos esses elementos, os elementos de interação, o foco no palco e as intervenções na cidade, para mim, tudo isso está lá desde o começo. Quando fizemos trabalhos, até mesmo antes de fundarmos o Rimini Protokoll, eles eram projetos site-specific e projetos interativos.

Mesmo no começo, por exemplo, fizemos Kreuzworträtsel Boxenstopp (2000), a primeira peça que fizemos aqui em Frankfurt. É uma peça com quatro senhoras idosas de um asilo, que está localizado numa casa vizinha do Künstlerhaus Mousonturm, onde se entra hoje no caminhão de DO's \& DON'Ts Eine Fahrt nach allen Regeln der Stadt. É onde nós, vinte anos atrás, observamos a coreografia das pessoas idosas lentamente entrando e saindo do asilo. É onde tudo começou de alguma maneira. É sempre legal estar aqui e olhar para esse lugar. É claro que todas as idosas já faleceram. Foi onde tudo começou, nessa vizinhança. Depois tivemos mais uma peça em que trabalhamos com o campo de documentação e de especialistas do cotidiano.

Em 2002, nas duas próximas peças, nós convidamos as pessoas para irem com a gente num edifício alto e do andar mais alto olhar para a rua abaixo. E nós pedíamos para que as pessoas contassem o que estavam vendo olhando para a multidão. E uma pessoa, por exemplo, estava focando em capital humano em comparação com outra pessoa que estava focando nas questões psicológicas envolvidas na relação de multidão, e assim por diante. E a outra peça copiava o 
debate do Parlamento. Então, eu não tenho a sensação que tenhamos tido primeiro um grande período com peças com especialistas e depois peças mais interativas e agora estamos voltando. Eu vejo as pessoas descrevendo assim, mas para mim é diferente. Para mim são elementos que nós sempre combinamos. Houve tempos em que estivemos um pouco mais no palco e houve tempos em que estivemos um pouco mais com projetos interativos e trabalhando com instalações.

\section{Qual a relação que você vê do Rimini Protokoll com a tradição teatral alemã ou internacional?}

Nós estamos ensaiando, aqui em Frankfurt, Chinchilla Arschloch, waswas (2018), a peça que estreamos no começo de abril. E para isso estivemos hoje falando sobre Publikumsbeschimpfung de Peter Handke, que teve sua estreia em 1966. A situação aconteceu em Frankfurt no Theater am Turm, há um interessante documentário em preto e branco sobre isso.

O interesse de todo o festival em que estreou Publikumsbeschimpfung era a transmissão pela televisão do que estava acontecendo no teatro. O que você vê são quatro atores e eles tem um texto que mais ou menos descreve o que o teatro é. Numa forma muito interessante de descrição por listas, com descrições muito claras, muito acuradas da relação entre a audiência, por um lado, vindo de fora com sua expectativa, seus desejos e suas demandas e a situação daquelas quatro pessoas em pé no palco tentando ter uma clareza sobre a situação em que elas estão dentro, em que nós estamos dentro no teatro. E o resultado foi muito acurado, houve muita reação, pessoas gritando, muita interação. É uma peça muito interessante de ler e é interessante assistir esse documentário. Seguidamente, no meu trabalho, quando eu começo um projeto, eu percebo quanto as questões são conectadas com o que aconteceu cinquenta anos atrás. Eu não leio esses autores, eu não gosto da maneira de dirigir do diretor dessa peça, mas dentro dessa situação, dentro desse marco temporal de cinquenta anos, é algo muito fascinante, algo que é muito inspirador. Eu fiquei surpresa. 
Eu me inspiro normalmente mais com as artes plásticas, com arte conceitual. Eu gosto do modo como as coisas podem permanecer simples nas artes plásticas. Porque no teatro, nós sempre temos que fazer as coisas se tornaram complexas, nós temos que misturar tudo, vídeo, atuação e som. Eu sou muito inspirada por simplicidade, quando há um único pensamento claro e eu consigo atingir esse único pensamento claro. Mas certamente há uma longa tradição teatral interessante. No nosso caso, nós somos muito ligados a Frankfurt, porque nós começamos em Giessen, que é muito perto de Frankfurt. E muitos das peças e performances que me inspiram, eu vi em Frankfurt, nos anos 1990, peças pósdramáticas, que tentavam contar ou mostrar as coisas de um modo diferente. E criar uma situação para o espectador, com o potencial, com o fascinante potencial que tem estar nesse lugar em tempo presente com a plateia e fazer algo.

\section{Como o fato ter estudado em Giessen foi importante na escolhas estéticas que motivam o seu trabalho no Rimini Protokoll?}

O que acontece em Giessen é que não se desenvolve habilidades específicas. Em Giessen, todos os estudantes são o que chamamos de profissionais diletantes. Nós do Rimini Protokoll experimentamos esse modo de aprendizagem. O que acontece no começo do curso, é que você faz um pouco de tudo. Você monta seus próprios vídeos, você edita seu próprio som, você performa, você faz shows, você lê textos, você faz tudo o que pode fazer. Para mim, foi um laboratório muito importante. A cidade não é muito atraente, não há muito a fazer. Então, as pessoas vão a universidade e trabalham, criam coisas, gastam tempo lá criando, se perguntando, seguindo suas questões de pesquisa. Cedo, nós percebemos que seria bom se a gente anunciasse dias abertos de apresentações, para colocar pressão em nós mesmos, de vez em quando abrindo as portas e deixando as pessoas assistir. Porque, de outra maneira, nós ficaríamos nadando em círculos nessa piscina e gostando dessa piscina da pesquisa e dos ensaios. E para mudar esse modo, agora é o momento da apresentação, então, vamos pensar mais rápido e tomar decisões mais cedo. Essa foi um caminho muito importante. Daniel e eu 
estudamos ao mesmo tempo, mas Stefan entrou lá depois. Eu já tinha partido quando ele entrou. Então, não estudamos realmente os três ao mesmo tempo.

É também um tipo específico de linguagem que você aprende lá, uma maneira de pensar. Seguidamente nós construímos equipes aqui ainda com pessoas que conhecemos lá, porque percebemos que nos entendemos, temos de alguma maneira o mesmo vocabulário. A mesma forma de abordar uma tarefa de criação teatral.

\section{Você tem um interesse especial em peças radiofônicas. Poderia contar um pouco mais sobre isso.}

Eu realmente gosto. Normalmente o processo acontece de modo inverso. Eu crio as peças radiofônicas depois de ter criado as peças teatrais. Eu volto aos

elementos das peças com os protagonistas. É um processo inverso. Não é apenas a documentação de uma peça, mas são novas gravações e uma nova maneira de contar uma história. É uma forma de contrabalançar, depois de ter feito uma peça, com todos os elementos teatrais, eu acho fascinante poder restringir-me a um elemento, o áudio. E também editando a peça radiofônica você pode criar a peça radiofônica perfeita, em oposição às apresentações teatrais que dependem do momento, uns dias são melhores, nos outros não tão boas. É claro que eu também gosto da apresentação teatral ser aquilo que acontece no momento, mas as peças radiofônicas oferecem um contrabalanço a isso. Eu gosto de desaparecer nos headphones de vez em quando e criar essas peças perfeitamente editadas.

\section{Essa é uma forma pouca explorada no Brasil. Ela tem público na Alemanha?}

É uma forma bem alemã. As peças radiofônicas são algo muito conectado com a nossa cultura. Isto porque depois da guerra não havia mais um sistema central de rádio, porque na guerra foi destruído o controle central. Assim, cada 
área, cada província na Alemanha, tem sua própria estação de rádio, essa foi uma decisão política. Eles pensaram: "Bom, nós temos essas estações de rádio para produzir notícias, então, vamos usá-las também para produzir arte”. Muitas das pessoas de teatro na Alemanha trabalham também para o rádio.

No Brasil, estamos tentando pensar em formas teatrais que possam oferecer alternativas ao discurso fascistas que se levanta no mundo com Trump, Bolsonaro, AfD, Le Pen, entre outros. Que formas teatrais você acha que podem ser usadas nesse momento de ressurgimento do discurso fascista?

Isso é difícil. Não seria fascista dizer que há apenas uma forma artística para usar? Talvez a pluralidade de formas artísticas seria minha resposta. Tentar ser diverso, fazer muitas coisas diversas, invés de ser um, de fazer apenas uma coisa. Ser subversivo, num sentido, é fazer coisas inesperadas. Eu nunca recomendaria a alguém fazer algo dessa ou daquela maneira, mas o melhor é tentar encontrar o que é surpreendente. No Brasil é muito mais difícil porque os fundos de cultura e institutos estão sendo fechados. Talvez não possamos realmente comparar a situação globalmente. A situação é muito dramática no Brasil e eu não sou a pessoa a vir com ideias prontas. Mas, definitivamente, a qualidade e o inesperado são as forças subversivas que o teatro e a arte têm.

\section{E na Alemanha? Com o crescimento da AfD (Alternative für Deutschland)?}

Isso depende se você quer trabalhar nas instituições estatais. Nas instituições estatais, isso está acontecendo na Alemanha também, eles tentam influenciar no programa, eles tentam influenciar o conteúdo. Quem está recebendo o dinheiro é uma grande questão para eles e quando se quer trabalhar profissionalmente é claro que o dinheiro importa. Assim, se torna importante sair das instituições, tentar dar mais força para se fazer o trabalho independente, onde se consegue ser visível de outro modo. Talvez seja importante sair dos muros das instituições e ir 
lá fora. Isso está acontecendo, essas formas já estão aparecendo. As formas de protestos estão se tornando mais artísticas. Talvez a arte esteja um pouco mais em formas de protesto novamente, isso tudo está novamente se misturando bastante.

Referencia

LEHMANN, Hans-Thies. Teatro pós-dramático. São Paulo: Cosac \& Naify, 2007.

Recebido em: 15/10/2020

Aprovado em:26/11/2020 